\section{New paradigms in the mechanisms and management of glaucoma}

HA Quigley

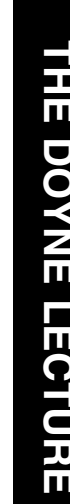

hence, the subtitle: 'from populations to apoptosis'.

During the last 30 years, the definition of glaucoma as been revised to eliminate the inclusion of intraocular pressure. Open angle glaucoma is the second leading cause of blindness in the world, but the proportion of those with the disease who become blind is low. Diagnostic methods for glaucoma need improvement. The pathogenetic steps to loss of neurons in glaucoma are increasingly understood and nonpressure lowering therapies are on the horizon. Eye (2005) 19, 1241-1248. doi:10.1038/sj.eye.6701746; published online 29 October 2004

Keywords: glaucoma; treatment; retinal ganglion cell; prevalence; pathogenesis

\section{Introduction}

The Doyne Lecturer has spoken about glaucoma on several past occasions. The lecture published in 1975 by Stephen Drance dealt with the correlation of clinical optic disc and visual field findings. ${ }^{1}$ At that time, perimetry was manually performed and the disc was photographed, not digitally imaged. Laser iridotomy and trabeculectomy were just entering the therapeutic regime, and laser angle treatment did not yet exist. Few ophthalmologists used gonioscopy and timolol had not yet been approved for use.

In the ensuing 30 years, our concepts of glaucoma have changed dramatically, as have the approaches to therapy. Yet, several new paradigms have not moved into the mainstream of thinking and practice of ophthalmology. The purpose of this anthology is to summarize ideas that impact both fundamental thinking about glaucoma and its daily management. It begins with information based in community studies from around the world and finishes with the death processes of retinal ganglion cells (RGC);

\section{Definition of OAG: normal tension glaucoma is dead}

We now recognize that glaucoma should be defined by damage to RGC, as detected by optic disc exam and visual field testing. No longer is open angle glaucoma (OAG) the 'disease of elevated IOP'. The most definitive evidence that a person has glaucoma is documented, progressive change in optic disc appearance and reproducible worsening in automated visual field testing. In practice, and in research and public health studies of glaucoma, these are rarely used as actual defining features, since the disorder alters RGC number and function so slowly. An operational definition of glaucoma has been proposed by Foster et al, based on consensus meetings among those who study glaucoma. ${ }^{2}$ It proposes that certain features are so likely to represent glaucoma damage that they can be used practically to denote the likelihood that progressive change has already occurred. For any population of interest, the relevant disc finding is a cup/disc ratio that represents the $97.5 \%$ ile for that group - typically equal to 0.7 for many groups (including Europeans). The field finding is an abnormal hemifield test result on the Zeiss/ Humphrey automated test, combined with at least three test points that exceed a high level of abnormality compared to age-normal data. This definition requires the acceptance of several assumptions, and will benefit from future comparison to alternative approaches.

However, it represents a practical approach to comparison of results in studies conducted in different locations.

There is no IOP criterion used in the definition of OAG. This dramatic change in thinking came from the clinical observations of Drance and others, as well as
Wilmer Ophthalmological Institute, Johns Hopkins Hospital, Baltimore MD, USA

Correspondence: HA Quigley, Ophthalmology Department, The Johns Hopkins University, 720 Rutland Avenue, Baltimore MD, USA Tel: + 1410955 2777; Fax: + 14109552542 E-mail: hquigley@ jhmi.edu

Received: 6 August 2004 Accepted: 7 September 2004

Published online: 29 October 2004 
the population-based data from the Baltimore survey ${ }^{3}$ and many other studies, presented in the 1996 Doyne Lecture by Alfred Sommer. ${ }^{4}$ Persons in population-based surveys who have disc and field findings meeting the OAG criteria suggested by Foster et al have untreated IOP in the normal range for their ethnic groups about half the time. This is true, whether the group consists of villagers in Tanzania, ${ }^{5}$ Hispanic citizens of the southwest United States, ${ }^{6}$ ethnic Chinese in Singapore, or Australians of European descent. ${ }^{7}$ We have known since the pioneering epidemiological work of Hollows and Graham $^{8}$ nearly 40 years ago that many persons with OAG have normal levels of IOP. Yet, we continue to label these persons with a different diagnosis (low tension or normal-pressure glaucoma). Furthermore, some ophthalmologists inform them that their disease is 'different', they question whether IOP-lowering is efficacious for those with OAG at normal IOP, and they terrorize them by performing brain imaging studies to look for nonexistent tumours. It is time to bury the corpse of low-tension glaucoma, and to cease using $21 \mathrm{mmHg}$ as a meaningful value. OAG is not a disease of elevated IOP. The higher the IOP, the greater the risk of damage and progression. The Collaborative Normal Tension Glaucoma Study demonstrated to a reasonable certainty that the lowering of IOP is as beneficial for those with OAG in the normal range ${ }^{9}$ as for those with higher IOP. ${ }^{10}$

We should use the baseline and target approach detailed below for management. In addition, it should be obvious that research studies should no longer segregate persons with OAG by a single arbitrary IOP criterion (the infamous 21). When only those with lower IOP are studied, the sample size for determining an effect is artificially made smaller. Furthermore, it is a priori just as likely that the factor of interest is associated with glaucoma at higher IOP as at lower IOP. Hence, the truncation of the group by a single criterion takes the chance of missing a real association that is sought. For example, it is logical that the perfusion of the nerve head is more challenged at higher than at lower IOP. Hence, in studies of nutrional blood flow, we should include those with higher as well as lower IOP, lest important risk factors be missed. Finally, the true association between IOP and a glaucoma risk factor can best be sought by using IOP as a continuous variable, or at least by subdividing into multiple IOP levels. In this case, good science and good clinical practice both demand that we cease to allow the publication of reports in glaucoma that perpetuate an outmoded concept.

\section{Prevalence of glaucoma}

Recent evaluations of the impact of glaucoma have demonstrated that OAG and angle closure glaucoma
(ACG), together, represent the second leading cause of blindness worldwide. ${ }^{11,12}$ Cataract leads to far greater morbidity, and trachoma is nearly as important as glaucoma as a cause of blindness. OAG is probably twice as common in the world as ACG, but the rate of blindness from ACG is substantially higher, leading to nearly 4 million persons bilaterally blind from each condition. ${ }^{13}$ There are five times more ACG in China and South Asia compared to European and African populations. ${ }^{14}$ This is the subject of a recent speculative review. ${ }^{15}$

Among the world's ethnic populations, OAG is least prevalent among Europeans, somewhat more prevalent in Hispanics ${ }^{6}$ and Indians, ${ }^{16}$ and affects Africans ${ }^{5}$ and African-derived groups most. ${ }^{3,17}$ The age-specific prevalence of OAG among black persons is four times greater than that of white persons. This difference is most likely to have a genetic basis, as the prevalence of OAG in Tanzanian villagers and black residents of East Baltimore, USA is quite similar, despite huge differences in diet, culture, environment, and health care delivery. However, studies that have attempted to divide persons by ethnicity must keep in mind that China or Africa consist of many groups of widely differing background, and simplistic generalizations must take this into account. The terms Hispanic or black also may be so variable in usage and definition that they are more sociocultural phenomena than measurable scientific criteria.

The world's population is ageing, and since age is a primary risk factor for OAG and ACG, we can expect that more glaucoma will require monitoring and therapy in the near future. In the USA, it is estimated that there will be $50 \%$ more persons with glaucoma within 15 years. ${ }^{18}$ In Asia and India, it is probable that increased numbers of older citizens will swell the ranks of those with glaucoma even more. While visual impairment is a tragedy for any of the world's citizens, for those in the poorest countries, blindness is associated with four times greater mortality. ${ }^{19}$ If we fail to solve the problem of glaucoma in developing countries, there will be premature death for tens of thousands. Fortunately, for the developed world, there is no confirmed reason to believe that OAG leads to greater mortality.

\section{Incidence and models of glaucoma}

The nature of OAG can be modelled through the use of available information. For example, we derived the rate at which new cases of OAG develop in populations (incidence), in order to calculate the length of time each person suffers from OAG and its rate of progression. Since persons who develop OAG do not undergo spontaneous cure and do not die at a greater rate than the 
general population in developed countries, Leske and coworkers ${ }^{20}$ proposed that incidence could be calculated from the increase in prevalence from 1 decade of life to the next. If there are $2 \%$ affected at the age of 40 years and $4 \%$ at the age of 60 years, then the incident rate could be estimated as $2 \%$ over 20 years, or $0.1 \%$ per year. Using this approach, we calculated the incident rate of OAG for European- and African-derived persons, ${ }^{21}$ and derived values that have generally been consistent with actual measurements of incident OAG in Australia ${ }^{22}$ and Barbados. $^{23}$

A life-table model predicts what will happen to a theoretical group of persons when the incident rate of OAG is applied to them through their expected life. This tells us that the average person develops OAG in their mid-60s, and has the disease for about 13 years (in white persons) or 16 years (in black persons). ${ }^{21}$ Calculations were made of the rate of worsening due to OAG over time, using the prevalent degree of glaucoma injury at each decade in a population. This suggested that OAG proceeds rather slowly on average, even when the effects of treatment were taken into account. ${ }^{24}$ The typical person with OAG was estimated to progress by the equivalent of a new scotoma in one hemifield during 15 years of disease. This is the mean behaviour of the disease, with many persons having even less progression and, unfortunately, some undergoing more rapid and severe progression.

Our model data were confirmed by studies and clinical trials, including the Collaborative Normal Tension Glaucoma Study, the Advanced Glaucoma Intervention Study, and the Collaborative Initial Glaucoma Study. Meta-analysis of these trials leads to the conclusion that $4 \%$ of glaucoma patients undergo visual field worsening per year. This event rate is fairly consistent across several studies, including one carried out on the Wilmer Glaucoma service, ${ }^{25}$ despite variations in the criteria for 'worsening'. Among untreated OAG subjects, the rate of worsening is about twice as high ( $8 \%$ per year). When one uses a parametric variable to estimate progression, the average treated OAG case loses about $0.1 \mathrm{~dB}$ of mean sensitivity per year. ${ }^{26,27}$

The authors of the Collaborative Normal Tension Glaucoma Study state: 'Given the slow average rate of experiencing a minimal increment of deterioration, the clinician may not need to act in haste. It is reassuring that among those who enrolled in the study with a fixation threat manifest on visual field examination and who were immediately randomly assigned not to be treated, only one had a change in acuity or foveal threshold develop that was not attributed to cataract formation. We could thus not find either a high risk of progression or a particularly rapid evolution to a visual handicap. ${ }^{27}$ Our efforts need to be directed to determine which of those with OAG are most rapidly progressive. These should be treated aggressively to achieve a low IOP. Among the remainder, it is clearly worthwhile to monitor function and to lower IOP; however, we must avoid putting persons with only slowly progressive disease at risk for iatrogenic damage. Our most urgent need is to implement methods for detection of progressive change that are efficient and widely applicable.

The logical conclusion from data showing only modest progression among those with OAG is that blindness is an uncommon event. Indeed, even in settings where no therapy is provided and OAG prevalence is high, 5,28 fewer than $10 \%$ of those with disease will become bilaterally blind by World Health Organization criteria. Some clinic-based ${ }^{29}$ or hospital-based ${ }^{30}$ analyses have suggested that the blindness rate per case is in this range or somewhat higher. It is obvious that those with blindness in one or both eyes would be more likely to present for care, thus making population-based data more accurate for the estimation of the true rate. Furthermore, there are those with OAG who are not blind but are significantly impaired. Nonetheless, it is not correct to describe OAG as a disorder that 'ultimately leads to blindness', if this implies that most of those with the disease become blind. Our initial conversation with newly diagnosed OAG patients should stress the overwhelmingly good chance that they will retain their vision - which can best be assured by continuous monitoring and compulsive cooperation with therapy regimes.

It would be incorrect to conclude that this review paints the risk of vision loss from OAG as trivial. However, we must understand that the following facts are now evident: (1) OAG progresses slowly in most of those affected; (2) OAG blinds only a small minority of those with disease; and (3) since OAG is a highly prevalent disease in older adults, the absolute number of those impaired by OAG is large.

\section{Case identification}

Population studies in developed countries found that at least half of those with OAG were unaware of their disease, ${ }^{3}$ and a further group were diagnosed but had dropped out of care. Clearly, we would like to identify those who are at risk for impairment and who could be successfully and effectively treated. In the developing world, nearly all persons with OAG are undiagnosed and untreated. When faced with the huge task of identifying and placing under care the many persons with glaucoma, we may be tempted to rush out into a mobile van with ophthalmoscope, tonometer, and a field test to spend a heartfelt weekend day. Such approaches are frustrated by several realities. ${ }^{31}$ The unpleasant truth 
is that methods for mass OAG screening are neither practical nor effective. Tonometry using an arbitrary cutoff level is much more likely to identify someone who will never develop glaucoma damage than a potential sufferer. Likewise, single tests of either disc or field have poor sensitivity and specificity. ${ }^{32}$

When a sample of persons undergoes a test for glaucoma, there are four possible outcomes: those with glaucoma are positive or negative and those who do not have glaucoma are positive or negative. The sensitivity of the test is the proportion of glaucoma cases who are positively identified, while the specificity is the proportion of nonglaucoma subjects whose test is negative. Clearly, the prevalence of the condition affects the predictive value of a screening test. For an OAG screening test with sensitivity of $80 \%$ and specificity of $90 \%$ applied to African-derived Barbadians over the age of 65 years (where OAG prevalence is $10 \%{ }^{17}$ ), screening of 100 persons will detect eight of the 10 glaucoma cases and will misidentify nine persons who are normal as glaucomatous. Thus, about half of those who screen positive $(8 /(8+9)$, or $47 \%)$ have the disease, and the burden of sorting out those who actually are normal is manageable. However, if we screen European-derived US 40 year olds in Baltimore (OAG prevalence 0.5\%), among 1000 screenees, the test detects four of the five true glaucoma cases, but calls 100 normal persons abnormal. The positive predictive power is only four in 104 or about $4 \%$.

The cost effectiveness of general OAG screening of whole populations has been found to be insufficient to justify public health attention. ${ }^{33,34}$ Newer methods must be devised that have sufficient likelihood of separating those with glaucoma from the unaffected in the population. One such idea is a function test that is low cost, battery-operated, and worn as goggles (similar to an indirect ophthalmoscope). Several types of target could be incorporated into such a device, including frequency doubling or high-pass stimuli. Or, it is feasible to develop a laser-based imaging device (linked to a national reading centre) that could remotely acquire disc and nerve fibre layer data on large numbers of persons at physicians offices, drivers' license bureaus, or shopping malls to determine who merits further glaucoma evaluation.

In a mass screening programme conducted for 7 years in Baltimore, ${ }^{35} 16000$ African-derived, urban citizens over 40 years of age were tested at senior housing centres and churches. Data analysis for 5000 of these persons showed that 2000 met referral criteria, 1300 scheduled a definitive examination by our ophthalmologists, but only 552 actually completed the full exam. Since we offered ophthalmic exams at no cost, we interviewed by telephone 500 persons who failed to keep their definitive exam to learn why they did not come. They cited forgetfulness, conflicts with work, and problems with transportation. We eliminated these issues for them and rescheduled $71 \%$ of these 'no-shows' for a second definitive examination. Only $25 \%$ of the rescheduled second appointments were kept. The inability to induce those at risk of asymptomatic disease to access free initial care is not unique to glaucoma programmes. As in hypertension programmes, $50 \%$ of those at risk are inherently concerned enough for their own well-being to accept offered care. Another 20-30\% are amenable to the extramotivational attempts and education. A final group of $10-20 \%$ are recalcitrant to multiple efforts.

Until research brings a higher technology solution to the screening problem, what can be done? There is a group of persons who have at least a $20 \%$ risk of OAG and we can obtain their addresses and telephone numbers. These are the close family members of those already diagnosed with OAG, whose personal contact information can be obtained from the proband. The chance of a parent or sibling of a known case having OAG is more than 10 times the population prevalence. ${ }^{36}$ A sibling or parent of a white OAG patient under the age of 70 years has a $10 \%$ chance of having OAG at this time (the rate is $20 \%$ for black persons). If an OAG patient has three living siblings, parents, or adult children, the chance that one of them has OAG now and does not know it is $27 \%$ for whites and nearly twice as high for blacks. For every eight cases of OAG, the family members contain one more with existing, undiagnosed glaucoma for Europeans and Asians, and two members among African-derived persons.

In the USA, there are 1.25 million known, diagnosed persons with OAG, who have approximately 3.75 million close adult relatives. There are, therefore, 158000 living relatives with undiagnosed glaucoma, and if the half were motivated to come for examination, we would detect 75000 new OAG cases with existing resources (about four to five new cases per ophthalmologist in the US). Surely this should stimulate the effort to approach those with glaucoma to contact their family and for ophthalmologists to offer aggressively examinations to family members. Our survey in a tertiary glaucoma service found that OAG patients often do not know whether their family members have been properly examined. We should urge definitive visual field testing on all family members.

Case identification in the developing world must remain for now in the realm of research study. Until it can be shown that therapies are both available and effective in these settings (even when shown to be so in the developed world), screening in any form is not ethical. Furthermore, while definitive glaucoma surgery has been shown to be acceptable in small pilot 
programmes, even in the most rural world locations, ${ }^{37,38}$ much more study is needed before appropriate public health measures can be devised.

\section{Overdiagnosis of OAG}

While undiagnosed glaucoma is frequent, it is equally distressing when persons are incorrectly told that they have glaucoma. Among the more common causes for this overdiagnosis is a thick cornea, as pointed out by the Ocular Hypertension Treatment Study. ${ }^{39}$ When we tell a patient that they have glaucoma and begin therapy, they not only incur the costs of treatment and the loss of quality of life attendant to the worry of blindness, but there is an increased risk of cataract, ${ }^{40}$ as well as health risks including increased cardiovascular disease with beta-blocker therapy. ${ }^{41}$

In addition to thick cornea, another reason for OAG overdiagnosis is the failure to recognize that large discs have large physiological cups. ${ }^{42}$ In African-derived persons, ${ }^{43}$ large discs are more common, and asymmetry in disc size is a common cause of cup/disc ratio asymmetry in persons who have no OAG. ${ }^{44}$ To avoid this problem, the disc size should be estimated either at the slit lamp through a variety of available low-tech approaches - or measured by an image analysis system that can alert the clinician to the normal variation. Confirmatory normal visual fields can reassure that OAG is not present. The availability of imaging devices, is, however, a two-edged sword. With several new machines, and rapidly changing soft and hardware, one must stay alert to the many times when an apparent 'abnormality' seen by imaging is simply an artefact and not disease. With each new generation of machines, there is a learning curve to decipher artefact from true abnormality. We must avoid making the same misdiagnostic mistakes with each subsequent technological change.

\section{Failure of therapy by default}

Among patients who are prescribed eyedrops for newly diagnosed OAG in the USA, how many are still taking the drops at the end of the first year? This question was studied in large databases of health maintenance organizations, ${ }^{45}$ where diagnosis was obtained by coding of the physician, and eyedrop use was judged by refilling behaviour of the same patient. It is likely that the data are an accurate reflection of how often patients take medication. Strikingly, over $50 \%$ of patients did not refill their initial eyedrop prescription by 1 year after diagnosis. Among participants in a US government health plan, with minimal cost to obtain drugs, $25 \%$ of newly diagnosed OAG subjects never filled the second prescription. ${ }^{46}$ The average number of days on which it is estimated that patients receive eyedrop glaucoma therapy is $70 \%{ }^{47}$

Poor cooperation with the taking of medicine is called lack of compliance, while stopping the drug altogether is called poor persistence. Again, the general literature on pills for hypertension adequately documents that a lack of compliance or persistence is not unique to glaucoma therapy. The typical ophthalmologist might respond that such poor patient performance does not occur in his/her office. This may be an accurate observation, since recent data show that not only do patients fail to persist in taking drops, but the same persons do not come back for follow-up. ${ }^{48}$ Hence, we do not see the behaviour because we only see those who are more likely to be complying. In our screening programme, the most effective question for identifying a person with OAG was to ask: 'have you already been told you have glaucoma (and are not in care now)?'

Are we simply up against recalcitrant human behaviour? No, to some degree the type of drugprescribed influences persistence, in that, once daily drops with few side effects are more likely to engender persistent use than two or three times per day regimens. Simplified regimens, drugs with fewer side effects, and careful instruction are likely to improve both compliance and persistence. More research is needed to determine how best to achieve effective glaucoma medical care.

\section{Beyond IOP-lowering for glaucoma therapy}

We must no longer 'normalize' IOP or lower IOP 'below $21^{\prime}$ as the goal of treatment. If we operationalize the concept that glaucoma happens at any IOP, then we must establish in each person the baseline, untreated IOP from which IOP-lowering will occur. We now have evidence that lowering of IOP by $20-30 \%$ decreases progressive worsening in OAG by 50-60\%. Target pressure systems were developed for several of the clinical trials, with goals such as 25 or $30 \%$ lowering. In addition, it is logical that the target pressure should be lower when there is substantial damage already present in the visual field. ${ }^{49}$

Some experts argue that we must lower IOP more drastically than $25-30 \%$ and that this might avoid any loss at all. While this is a hypothesis worthy of testing, it is possible that some portion of glaucoma injury is independent of the prevailing IOP, and would not be avoided by any pressure-based therapy. If we examine the process of RGC injury and death in glaucoma, we have clues about how new preventive strategies might arise for preservation of the maximum vision in glaucoma. In both experimental models and human eyes with glaucoma, RGC axons at the optic nerve head show anatomic and physiologic injury. ${ }^{50}$ More recently, the 
death of RGC was found to occur, at least for many neurons, through apoptosis, the reactivation of a programmed sequence of cell suicide. ${ }^{51,52}$ The most logical link between these two facts would be to suppose that axonal transport blockade from the injury to RGC fibres at the nerve head produced an obstruction in a vital messenger molecule that would normally arrive back at the cell body in the retina by retrograde movement. This fall in messenger would initiate apoptosis. In embryological life, RGC know that they are properly targeted to their brain centre by receiving the appropriate messenger from partner cells. When they are misdirected and fail to reach the right target, the lack of messenger leads to apoptosis. Our proposal is that this process repeats itself in adult life by the injury of glaucoma - in effect, pathology recapitulates ontogeny.

Indeed, we have shown that the important messenger protein, brain-derived neurotrophic factor, is blocked in movement back to the RGCs in experimental glaucoma, ${ }^{53}$ and when it is provided to RGC by gene therapy in experimental glaucoma, a substantially lower number of RGC die, without lowering of IOP. ${ }^{54}$ This could be a therapy that is combined with IOP-lowering; indeed, since we know that a lower IOP is beneficial, it would be clearly unethical not to lower IOP in those with glaucoma. Thus, all non-IOP treatments will be tested by their additive protective value in the face of IOPlowering. Another gene therapy success was reported by McKinnon et al, ${ }^{55}$ when they inserted a gene that blocks a late stage of enzyme activation in the apoptosis process, again in the rat glaucoma model. Any method that prevents RGC death and preserves their function would be a welcome addition to our armamentarium. However, it makes sense to attempt to interrupt the process as early as possible in the cascade of pathological events.

Some early events occur at the interface between the RGC axon and its supportive and nutritional tissues in the nerve head. The level of IOP is transmitted to RGC by the corneoscleral shell, most critically the connective tissues of the nerve head that contain collagen and elastin. Failure to retain normal elasticity could be an initial link between IOP and RGC injury. ${ }^{56}$ In order to recognize that axonal shape is being altered by external forces, pressure sensitive channels (TRAAK channels) may be the operative pathway. ${ }^{57}$ RGC axons might be made less sensitive to compression through manipulation of TRAAK channel sensitivity. A molecule that deserves study, the motor protein that carries messenger proteins on their receptors, is dynein, a huge complex riding along the axonal microtubules. It requires substantial ATP-provided energy to bring messengers back to the RGC body, and may be the nexus for action of failure in nutritional blood flow to the axons. Each of these 'upstream' areas deserves intense investigation for protective interventions.

Finally, there are a variety of other pieces of evidence linking various processes to RGC death in glaucoma. Free radical damage mediated either through nitric oxide synthesis $^{58}$ or glutamate excitotoxicity ${ }^{59}$ has been suggested as an event that is blocked to avoid RGC damage. Stimulation of immune-mediated phenomena by glatiramer has also been suggested to improve outcomes in experimental glaucoma. ${ }^{60}$ It is not clear how nitric oxide or glutamate toxicity relate to the other risk factors for glaucoma, or how they fit into the pathway from initial events to RGC death. It is possible that some RGC die from primary injury and that others are killed by secondary events initiated by the primary deaths. ${ }^{61}$ We may, then, be looking for neuroprotective approaches that block events in the IOP-initiated pathway or events that result from the disturbed environment produced in the retina and optic nerve by initial glaucoma damage that are IOP-independent.

The future of glaucoma therapy depends upon our ability to synthesize new information about this common condition, where blindness is now known to be largely preventable. In the future, I predict that we will bring the remainder of those with disease under observation. We can avoid the failures that come from improper diagnosis or treatment approaches, as well as from maladaptive patient behaviour. In addition, we should aim to provide comprehensive protective treatments that allow RGC to live, providing lifelong quality of vision.

\section{References}

1 Drance SM. Doyne Memorial Lecture, 1975. Correlation of optic nerve and visual field defects in simple glaucoma. Trans Ophthalmol Soc UK 1975; 95: 288-296.

2 Foster PJ, Buhrmann R, Quigley HA, Johnson GJ. The definition and classification of glaucoma in prevalence surveys. Br J Ophthalmol 2002; 86: 238-242.

3 Sommer A, Tielsch JM, Quigley HA, Gottsch JD, Javitt J, Singh K. Relationship between intraocular pressure and primary open angle glaucoma among white and black Americans: The Baltimore Eye Survey. Arch Ophthalmol 1991; 109: 1090-1095.

4 Sommer A. Doyne Lecture. Glaucoma: facts and fancies. Eye 1996; 10: 295-301.

5 Buhrmann RR, Quigley HA, Barron Y, West SK, Oliva MS, Mmbaga BBO. The prevalence of glaucoma in a rural east African population. Invest Ophthalmol Vis Sci 2000; 41: 40-48.

6 Quigley HA, West SK, Rodriguez J, Munoz B, Klein R, Snyder R. The prevalence of glaucoma in a populationbased study of Hispanics: Proyecto Ver. Arch Ophthalmol 2001; 119: 1819-1826.

7 Weih LM, Nanjan M, McCarty CA, Taylor HR. Prevalence and predictors of open-angle glaucoma: results from the Visual Impairment Project. Ophthalmology 2001; 108: 1966-1972. 
8 Hollows FC, Graham PA. Intra-ocular pressure, glaucoma and glaucoma suspects in a defined population. $\mathrm{Br} J$ Ophthalmol 1966; 50: 570-586.

9 Anderson DR. Collaborative normal tension glaucoma study. Curr Opin Ophthalmol 2003; 14: 86-90.

10 Heijl A, Leske MC, Bengtsson B, Hyman L, Bengtsson B, Hussein M. Early Manifest Glaucoma Trial Group. Reduction of intraocular pressure and glaucoma progression: results from the Early Manifest Glaucoma Trial. Arch Ophthalmol 2002; 120: 1268-1279.

11 Thylefors B, Negrel AD. The global impact of glaucoma. Bull World Health Organ 1994; 72: 323-326.

12 Quigley HA. The number of persons with glaucoma worldwide. Br J Ophthalmol 1996; 80: 389-393.

13 Foster PJ, Johnson GJ. Glaucoma in China: how big is the problem? Br J Ophthalmol 2001; 85: 1277-1282.

14 Foster PJ, Oen FT, Machin D, Ng TP, Devereux JG, Johnson GJ et al. The prevalence of glaucoma in Chinese residents of Singapore: a cross-sectional population survey of the Tanjong Pagar district. Arch Ophthalmol 2000; 118: 1105-1111.

15 Quigley HA, Friedman DS, Congdon NG. Possible mechanisms of primary angle-closure and malignant glaucoma. J Glaucoma 2003; 12: 167-180.

16 Ramakrishnan R, Nirmalan PK, Krishnadas R, Thulasiraj RD, Tielsch JM, Katz J et al. Glaucoma in a rural population of southern India: the Aravind comprehensive eye survey. Ophthalmology 2003; 110: 1484-1490.

17 Leske MC, Connell AM, Schachat AP, Hyman L. The Barbados Eye Study. Prevalence of open angle glaucoma. Arch Ophthalmol 1994; 112: 821-829.

18 Friedman DS, Wolfs RC, O'Colmain BJ, Klein BE, Taylor HR, West $\mathrm{S}$ et al. Eye Diseases Prevalence Research Group. Prevalence of open-angle glaucoma among adults in the United States. Arch Ophthalmol 2004; 122: 532-538.

19 Buhrmann R, unpublished data from the Kongwa Eye Survey.

20 Leske MC, Ederer F, Podgor M. Estimating incidence from age-specific prevalence in glaucoma. Am J Epidemiol 1981; 113: 606-613.

21 Quigley HA, Vitale S. Models of open-angle glaucoma prevalence and incidence in the United States. Invest Ophthalmol Vis Sci 1997; 38: 83-91.

22 Mukesh BN, McCarty CA, Rait JL, Taylor HR, Mukesh BN, McCarty CA et al. Five-year incidence of open-angle glaucoma: the Visual Impairment Project. Ophthalmology 2002; 109: 1047-1051.

23 Leske MC, Connell AM, Wu SY, Nemesure B, Li X, Schachat A et al. Incidence of open-angle glaucoma: the Barbados Eye Studies. The Barbados Eye Studies Group. Arch Ophthalmol 2001; 119: 89-95.

24 Quigley HA, Tielsch JM, Katz J, Sommer A. The rate of progression in open-angle glaucoma. Am J Ophthalmol 1996; 122: $355-363$.

25 Smith SD, Katz J, Quigley HA. Analysis of progressive change in automated visual fields in glaucoma. Invest Ophthalmol Vis Sci 1996; 37: 1419-1428.

26 Katz J, Gilbert D, Quigley HA, Sommer A. Estimating progression of visual field loss in glaucoma. Ophthalmology 1997; 104: 1017-1025.

27 Collaborative Normal-Tension Glaucoma Study Group. Natural history of normal-tension glaucoma. Ophthalmology 2001; 108: 247-253.

28 Wilson MR, Kosoko O, Cowan Jr CL, Sample PA, Johnson CA, Haynatzki G et al. Progression of visual field loss in untreated glaucoma patients and glaucoma suspects in St Lucia, West Indies. Am J Ophthalmol 2002; 134: 399-405.

29 Chen PP. Blindness in patients with treated open-angle glaucoma. Ophthalmology 2003; 110: 726-733.

30 Hattenhauer MG, Johnson DH, Ing HH, Herman DC, Hodge DO, Yawn BP et al. The probability of blindness from open-angle glaucoma. Ophthalmology 1998; 105: 2099-2104.

31 Quigley HA. Current and future approaches to glaucoma screening. J Glaucoma 1998; 7: 210-219.

32 Tielsch JM, Katz J, Singh K, Quigley HA, Gottsch JD, Javitt J et al. A population-based evaluation of glaucoma screening: The Baltimore Eye Survey. Am J Epidemiol 1991; 134: 1102-1110.

33 Gottlieb LK, Schwartz B, Pauker SG. Glaucoma screening. A cost-effectiveness analysis. Surv Ophthalmol 1983; 28 206-226.

34 Boivin JF, McGregor M, Archer C. Cost effectiveness of screening for primary open angle glaucoma. J Medical Screening 1996; 3: 154-163.

35 Quigley HA, Park CK, Tracey PA, Pollack IP. Community screening for eye disease by lay persons: the Hoffberger program. Am J Ophthalmol 2002; 133: 386-392.

36 Wolfs RC, Klaver CC, Ramrattan RS, van Duijn CM, Hofman A, de Jong PT. Genetic risk of primary open-angle glaucoma. Population-based familial aggregation study. Arch Ophthalmol 1998; 116: 1640-1645.

37 Quigley HA, Buhrmann RR, West SK, Isseme I, Scudder M, Oliva MS. Long-term results of glaucoma surgery among participants in an east African population survey. $\mathrm{Br} \mathrm{J}$ Ophthalmol 2000; 84: 860-864.

38 Nolan WP, Baasanhu J, Undraa A, Uranchimeg D, Ganzorig $\mathrm{S}$, Johnson GJ. Screening for primary angle closure in Mongolia: a randomised controlled trial to determine whether screening and prophylactic treatment will reduce the incidence of primary angle closure glaucoma in an east Asian population. Br J Ophthalmol 2003; 87: 271-274.

39 Gordon MO, Beiser JA, Brandt JD, Heuer DK Higginbotham EJ, Johnson CA et al. The Ocular Hypertension Treatment Study: baseline factors that predict the onset of primary open-angle glaucoma. Arch Ophthalmol 2002; 120: 714-720.

40 Leske MC, Heijl A, Hussein M, Bengtsson B, Hyman L, Komaroff E. Early Manifest Glaucoma Trial Group. Factors for glaucoma progression and the effect of treatment: the early manifest glaucoma trial. Arch Ophthalmol 2003; 121: 48-56.

41 Coleman AL, Diehl DLC, Jampel HD, Bachorik PS, Quigley HA. Topical timolol decreases plasma high-density lipoprotein cholesterol level. Arch Ophthalmol 1990; 108: 1260-1263.

42 Caprioli J, Miller JM. Optic disc rim area is related to disc size in normal subjects. Arch Ophthalmol 1987; 105: 1683-1685.

43 Varma R, Tielsch JM, Quigley HA, Hilton SC, Katz J, Spaeth GL et al. Race-, age-, gender-, and refractive error-related differences in the normal optic disc. Arch Ophthalmol 1994; 112: 1068-1076.

44 Ong LS, Mitchell P, Healey PR, Cumming RG. Asymmetry in optic disc parameters: the Blue Mountains Eye Study. Invest Ophthalmol Vis Sci 1999; 40: 849-857.

45 Schwartz GF, Reardon G, Mozaffari E. Persistency with latanoprost or timolol in primary open-angle 
glaucoma suspects. Am J Ophthalmol 2004; 137(Suppl 1): S13-S16.

46 Gurwitz JH, Glynn RJ, Monane M, Everitt DE, Gilden D, Smith $\mathrm{N}$ et al. Treatment for glaucoma: adherence by the elderly. Am J Public Health 1993; 83: 711-716.

47 Gurwitz JH, Yeomans SM, Glynn RJ, Lewis BE, Levin R, Avorn J. Patient noncompliance in the managed care setting. The case of medical therapy for glaucoma. Med Care 1998; 36: 357-369.

48 Kosoko O, Quigley HA, Vitale S, Enger C, Kerrigan LA, Tielsch JM. Risk factors for non-compliance with glaucoma follow-up visits. Ophthalmology 1998; 105: 2105-2111.

49 Jampel HD. Target pressure in glaucoma therapy. J Glaucoma 1997; 6: 133-138.

50 Quigley HA, Addicks EM, Green WR, Maumenee AE. Optic nerve damage in human glaucoma. II. The site of injury and susceptibility to damage. Arch Ophthalmol 1981; 99: 635-649.

51 Quigley HA, Nickells RW, Kerrigan LA, Pease ME, Thibault DJ, Zack DJ. Retinal ganglion cell death in experimental glaucoma and after axotomy occurs by apoptosis. Invest Ophthalmol Vis Sci 1995; 36: 774-786.

52 Kerrigan LA, Zack DJ, Quigley HA, Smith SD, Pease ME. TUNEL-positive ganglion cells in human primary open angle glaucoma. Arch Ophthalmol 1997; 115: 1031-1035.

53 Pease ME, McKinnon SJ, Quigley HA, Kerrigan-Baumrind LA, Zack DJ. Obstructed axonal transport of the neurotrophin receptor TrkB in experimental glaucoma. Invest Ophthalmol Vis Sci 2000; 41: 764-774.

54 Martin KRG, Quigley HA, Zack DJ, Levovitch-Verbin H, Kielczewski J, Valenta D et al. Gene therapy with brain- derived neurotrophic factor protects retinal ganglion cells in a rat glaucoma model. Invest Ophthalmol Vis Sci 2003; 44: 4357-4365.

55 McKinnon SJ, Lehman DM, Tahzib NG, Ransom NL, Reitsamer HA, Liston $\mathrm{P}$ et al. Baculoviral IAP repeatcontaining-4 protects optic nerve axons in a rat glaucoma model. Mol Ther 2002; 5: 780-787.

56 Quigley HA, Brown A, Dorman-Pease ME. Alterations in elastin of the optic nerve head in human and experimental glaucoma. Br J Ophthalmol 1991; 75: 552-557.

57 Maingret F, Fosset M, Lesage F, Laxdunski, Honore E. TRAAK is a mammalian neuronal mechano-gated $\mathrm{K}+$ channel. J Biol Chem 1999; 274: 1381-1387.

58 Neufeld AH, Sawada A, Becker B. Inhibition of nitric-oxide synthase 2 by aminoguanidine provides neuroprotection of retinal ganglion cells in a rat model of chronic glaucoma. Proc Natl Acad Sci USA 1999; 96: 9944-9948.

59 Hare W, WoldeMussie E, Lai R, Ton H, Ruiz G, Feldmann B et al. Efficacy and safety of memantine, an NMDA-type open-channel blocker, for reduction of retinal injury associated with experimental glaucoma in rat and monkey. Surv Ophthalmol 2001; 45(Suppl 3): S284-S289.

60 Schwartz M. Neurodegeneration and neuroprotection in glaucoma: development of a therapeutic neuroprotective vaccine: the Friedenwald lecture. Invest Ophthalmol Vis Sci 2003; 44: 1407-1411.

61 Levkovitch-Verbin H, Quigley HA, Kerrigan-Baumrind LA, D'Anna S, Kerrigan DF, Pease ME. Optic nerve transection in monkeys may result in secondary degeneration of retinal ganglion cells. Invest Ophthalmol Vis Sci 2001; 42: 975-982. 